\title{
A Study on the Perceived Mobile Experience of Myeg Users
}

https://doi.org/10.3991/ijim.v13i11.11306

\author{
Azham Hussain (凶), Emmanuel O.C. Mkpojiogu, \\ Norzila Ishak, Nurhidayah Mokhtar \\ Universiti Utara Malaysia, Kedah, Malaysia \\ azhamh123@gmail.com
}

\begin{abstract}
Mobility is the trend right now. It is transforming the user experience from the confines of the desk to the convenience of anytime-anywhere. MyEG Services Berhad ("MYEG") is a concessionaire for Malaysian Electronic-Government ("E-Government") MSC Flagship Application. MYEG builds, operates and owns the electronic channel that delivers services from various Government agencies to Malaysia citizens and businesses. To make their services up-to-date and in trend, MyEG app was developed and can also be used to check summons, pay summons, renew road-tax and renew auto insurance. To make sure that this application is efficient, fulfilling the customer needs and satisfaction, a usability evaluation was conducted. The evaluation was conducted in "Jabatan Teknologi Maklumat \& Komunikasi, Politeknik Seberang Perai", with 15 participants consisting of both lecturers and students. The think-aloud protocol was used while conducting the evaluation. The result of the evaluation revealed that overall the app is efficient, successful in fulfilling the users' requirement and needs and promotes users mobile experience.
\end{abstract}

Keywords-Mobile experience; think-aloud protocol; usability evaluation.

\section{Introduction}

The mobile MyEG app has undergone a complete transformation and offers new features. The new enhancements provide customers with easier accessibility to perform a variety of e-government transaction. The user need to login unto the MyEG app to gain access for the following services: renewal of road tax, renewal of auto insurance, checking and payment of PDRM summonses, checking and payment JPJ summonses, and the checking of deli-very status for requested MyEG services. Through this updated mobile app, users can quickly complete their e-government trans-actions at any time and any place [1-10]. 


\section{Methods}

The MyEG app usability test involved the use of the think-aloud protocol with a post-test questionnaire administered to participants. A representative number of users were recruited to carry out some representative tasks on the application. A facilitator recorded all the user actions and comments during the test session. After the users finished their assigned tasks, the facilitator then gives them a set of questionnaire to fill. The questionnaire collect data related to user's satisfaction about the user interface and the presentation of the application [11-19].

The roles of the personnel involved in the usability test were as follows: Facilitator: the facilitator coordinates, manages and directs the test session and the entire usability evaluation. He also records the participants' or testers' actions and comments. The facilitator briefs participants or testers on the usability evaluation. He defines the usability and the purpose of usability testing and responds to participants' requests for assistance while also observing them. He also conducts the debriefing sessions [2030]. Participants (Testers): The usability testing was run with 15 participants (or testers). These participants were either academic staff or students of Politeknik Seberang Perai. They were selected on the basis of their prior experience or lack of prior experience on the use of the MyEG app. The participants' ages ranged from 20 years old and above and included both genders. All participants were good in computer skills and these skills helped the participants a lot in the running of the test.

Two places were used for the conduct of the usability test. The first location was JTMK Office which was used for the testing with academic staff. The second location was JTMK lab for testing with students. Before the commencement of the test session, the facilitator briefed the participants on the purpose of the usability test for MyEg app. He explained the instructions to participants on what to do during the test and informed the participants that the object of evaluation was the application and not the participants themselves. After that, the facilitator introduced to participants how to use the MyEG application. He also gave a printed copy of the task description to the participants. There were task that require participants to read aloud the results that they got. Time-on-task began when the participants start their tasks. The facilitator then records the participants' actions and comments. After the participants have finished all the tasks, they were made to complete a satisfaction questionnaire. There were five tasks tested [31-43]. They are inter alia: i) install the application; ii) login into the application; iii) customize user profile; iv) check PDRM summonses; v) make a payment for PDRM summonses.

The task scenarios are as follows:

Task 1 Scenario: Install the application.

Instructions are as follows: Using android phone, try to install the MyEG mobile application.

Description: This task requires a participant to install the MyEG app using an android phone. Users' success rates in accomplishing this task will measure the effectiveness of the app while the time they expended to achieve success in the installations process measures the efficiency of the app.

The steps involved include: 
- The participant should find the "Play Store" on the android phone and then type MyEG at the Google Play search engine. After that, the participant will select the install button for the installation process

- If the installation process is successful, the participant will see the open button

- The user should then login into the application.

Task 2 Scenario: Login into the application. Instruction:

- From the home page of the android phone, try to login into the MyEG apps using the given ID and password. ID: ayumiesz; and Password: sonicz.

The steps involved include:

- After installing the MyEG app, the participant should try to login into the application using the information given, that is, he/she should key in his/her username and password and then click on the login button

- See error message if any exits.

Task 3 Scenario: Customize user profile.

Instruction: In login status, try to update user profile for item address and item phone number based on the information below:

- Phone number: 013 - 3425874

- Postcode: 13800

- City: Butterworth

- State: Pulau Pinang

- Address: No 234, Taman Saujana, Jalan Keramat.

The step involved include:

- In user profile, participant is required to click menu function and then choose edit profile

- At the edit profile, participant is required to update information based on the task instructions and then save the changes.

Task 4 Scenario: Check PDRM Summonses.

Instruction: in login status, try to check PDRM summonses based on the ID; e.g. ID: 840512105386

After the list of summonses is viewed at the android phone screen, the participant/tester must speak aloud on how many summonses he or she viewed.

The steps involved include:

- In login status, at the home page, participant is required to click check and pay PDRM Summons function and then insert the given ID Number

- After inserting the ID Number, participant then clicks the button, Check Summons. If the ID Number have summons, then a list of summons will be viewed.

Task 5 Scenario: Make a payment for PDRM Summonses. 
Instruction:

- In login status, select one PDRM summons and make payment for that summons using the information below to fill payment information.

- Card Type: Visa

- Card Expiry Date: $\mathrm{MM}=12$ and YYYY $=2019$

- Card Number: 4786704000080233

- Security Code: 011

- Card Holder Name: Norzila Ishak

- Card Issued By: Bank Islam Malaysia Berhad

- Tick authorized and then submit the payment

The steps involved are:

- After inserting the ID Number; click the button, Check Summons. If the ID Number have summons, a list of summons will be viewed

- Tick one summons and make payment. A click on the button pays 1 summons

- After that, confirm details will be viewed. Participants are required to click proceed to payment button and then payment details will be viewed

- Participants then make payment using credits card. To make payment, participants will click on credit cards (Master/Visa) button and then the credit card form details will be viewed

- Participants need to fill the credit card information using the given information at task 5. Next, participants will click the authorized button and then submit the form

- The MyEG app will process the information for the validation of card details.

Success or failure in these 5 tasks measures the effectiveness of the apps interface while the amount of resources (time and effort) expended in achieving these goals measures the efficiency of the interface.

Some equipment and materials used to support the usability evaluation are as follows:

- Android mobile devices: Android mobile devices were used to test the MyEG app. Participants used these devices to carry out the usability test

- Screencast Video Recorder application (Mobizen): The Mobizen app was used to record all of the user activities on the MyEG app. This app records the hand gesture/movement of the user while using the MyEG app

- Mobile-device camera: Mobile device camera was used by the facilitator to capture and understand the users' interaction and to capture their facial expressions

- Internet connection (Celcom First Gold Plus CBS): Internet was provided to make task 1 installation process successful

- Scripted instructions: These instructions guide participants in performing the tasks given to them

- Microsoft Office 2010 (Microsoft Excel and Microsoft Word): Microsoft Excel was used to calculate and analyse the data while Microsoft Word was used to write the report. 
The ISO/IEC 9241-11 standard was used as a guide in measuring the usability of the MyEG app. The standard postulates that usability is "the extent to which a product can be used by specified users to achieve specified goals with effectiveness, efficiency and satisfaction in a specified context of use". Table 1 below explains the attributes of usability and the metrics that were used to capture them [44-53].

Table 1. Usability Attributes and Associated Metrics Used

\begin{tabular}{|l|l|}
\hline \multicolumn{1}{|c|}{ Attributes } & \multicolumn{1}{c|}{ Metrics } \\
\hline $\begin{array}{l}\text { Effectiveness: The accuracy and complete- } \\
\text { ness with which specified users achieve } \\
\text { specified goals in particular environments }\end{array}$ & -Number of errors that occur while carrying out task \\
\hline & -Percentage of participants that completed their tasks \\
$\begin{array}{l}\text { Efficiency: The resources expended in } \\
\text { relation to the accuracy and completeness } \\
\text { with which users achieve goals }\end{array}$ & -Time taken by the user to learn how to use the application \\
& -Time taken to accomplish given task \\
\hline $\begin{array}{l}\text { Satisfaction: The comfort and acceptability } \\
\text { of use. }\end{array}$ & -Data entry time, time the user takes to fill up their information \\
\hline
\end{tabular}

\section{Results and Discussion}

The result of the usability evaluation is as follows: Demographics:

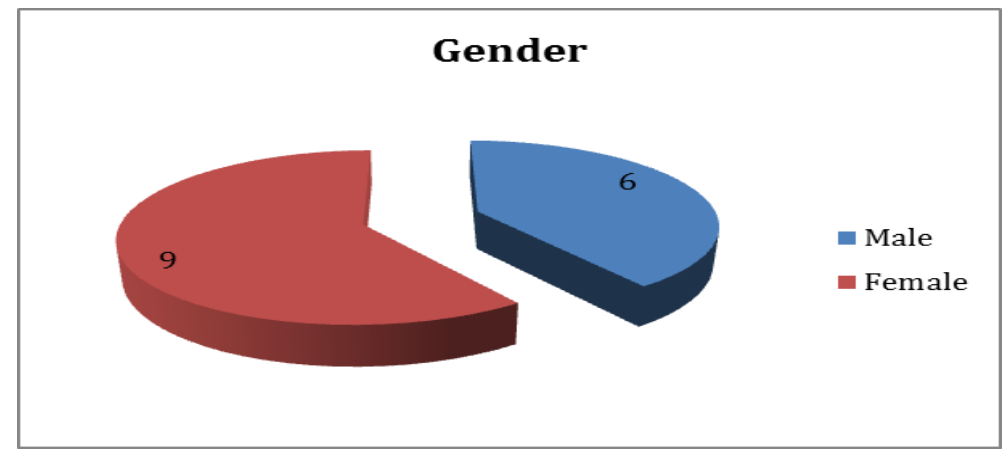

Fig. 1. Gender 


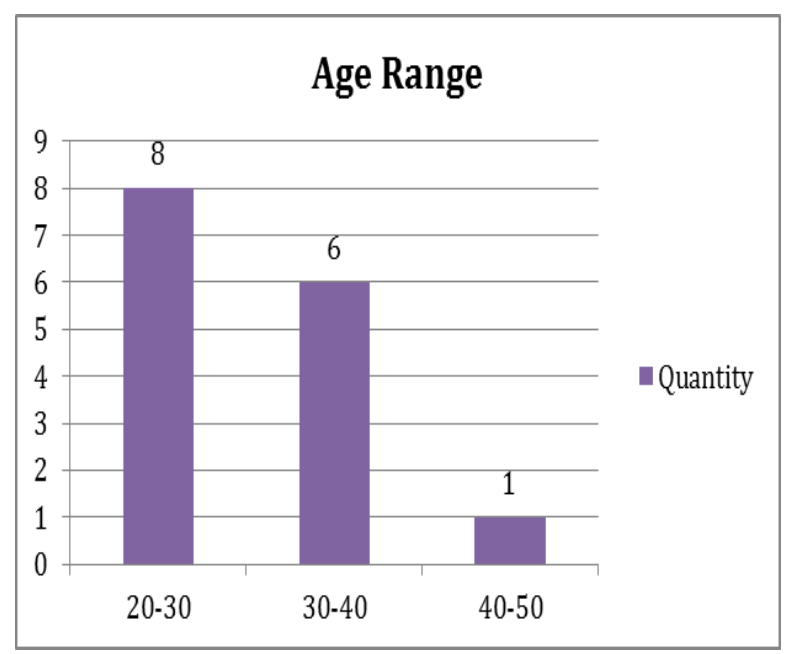

Fig. 2. Age

Figure 1 result shows that $60 \%$ i.e., 9 out of 15 of the respondents were females, while $40 \%$ were males. Also, Figure 2 shows that the highest number (8) $(53 \%)$ of respondents were within the age range 20-30, six (40\%) respondents were within the age range 30-40, while $1(7 \%)$ respondent was in the age range 40-50.

\subsection{Performance}

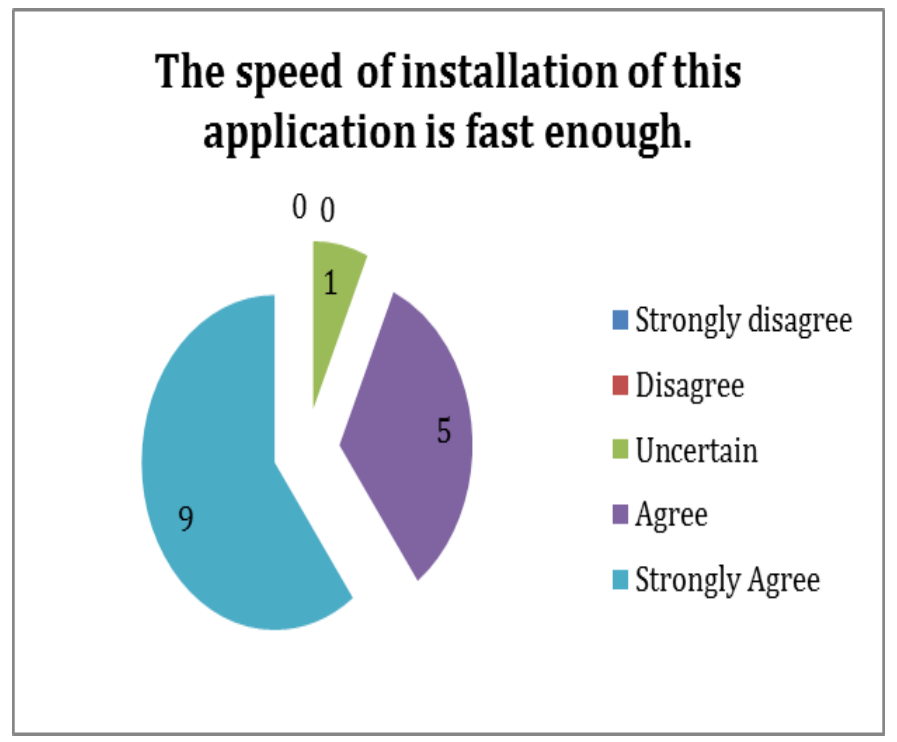

Fig. 3. Question 1 


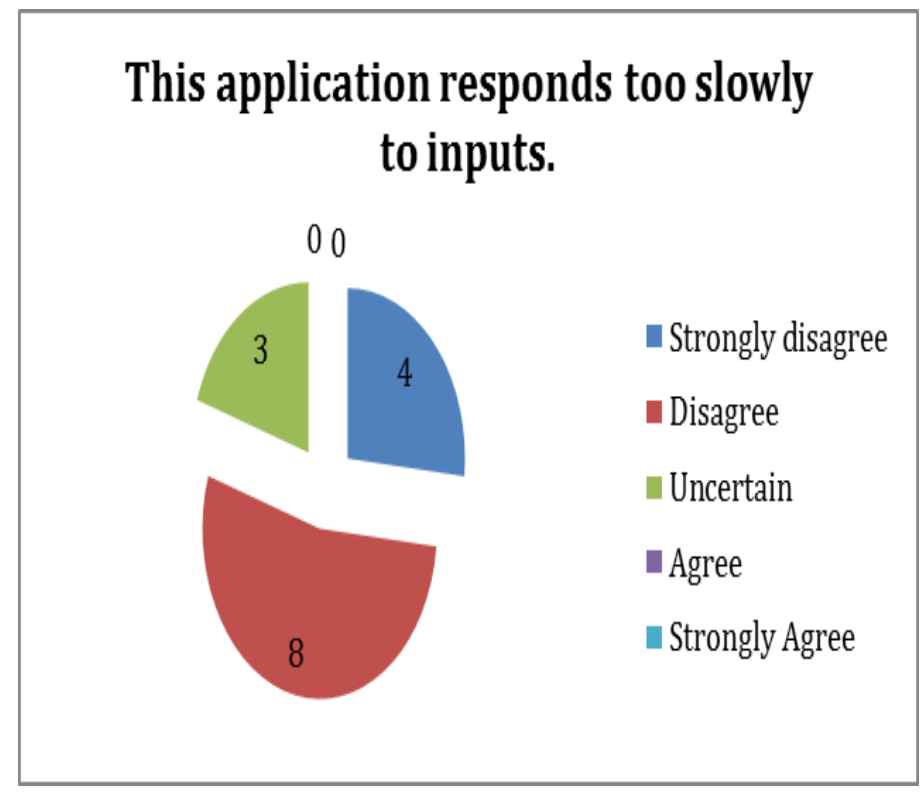

Fig. 4. Question 2

Figure 3 shows that of the 15 respondents, 14 (93\%) perceived that the speed of installation was fast enough. The speed of installation was actually influenced by the mobile data connection. In Figure 4, twelve (12) (80\%) respondents disagreed that the application responds too slowly to inputs.

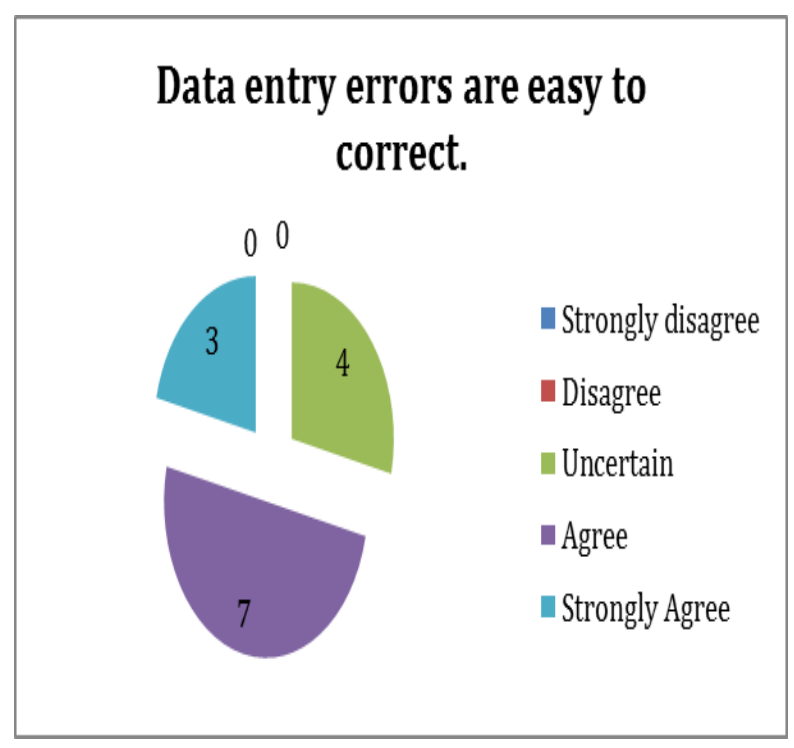

Fig. 5. Question 3 


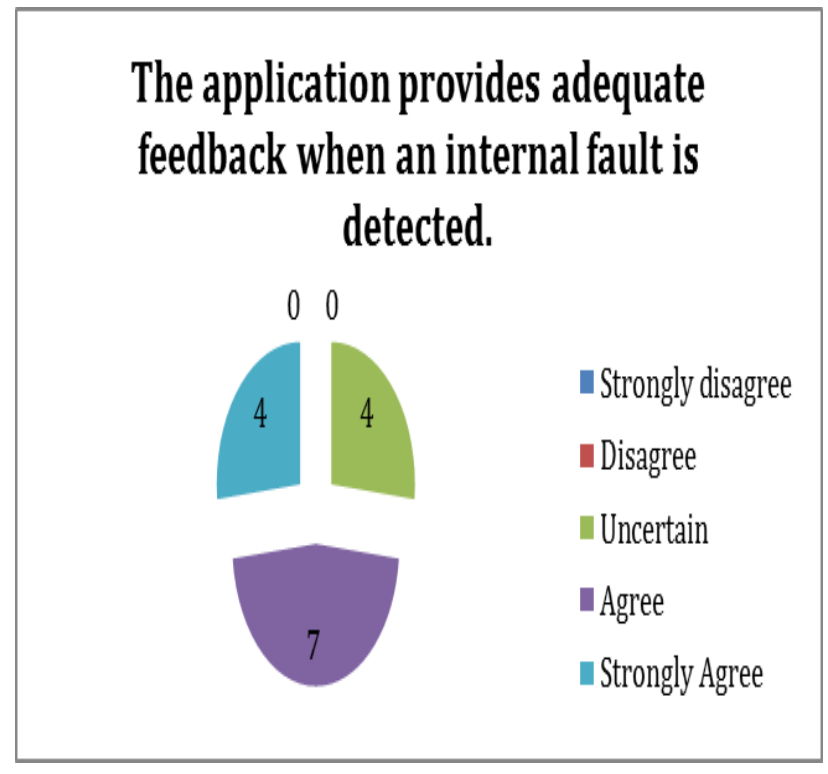

Fig. 6. Question 4

Figure 5 shows that 10 of $14(71 \%)$ respondents believed that data entry errors were easy to correct. One respondent failed to provide answer to this question. This made the total respondents for this question to be fourteen instead of fifteen. In Figure $6,11(73 \%)$ respondents feel that the application provides adequate feedback when an internal fault is detected.

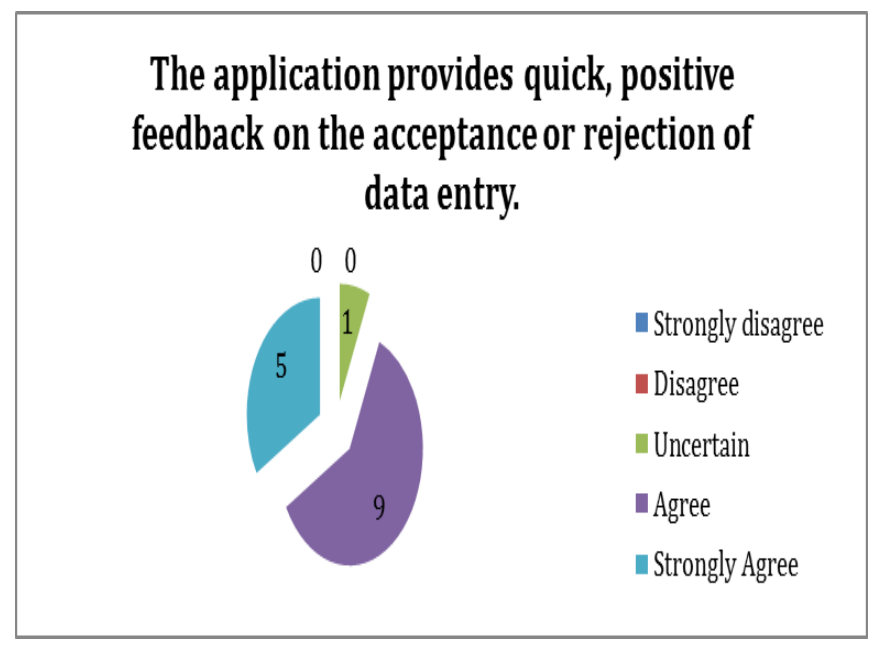

Fig. 7. Question 5 


\section{I get the site information quickly.}

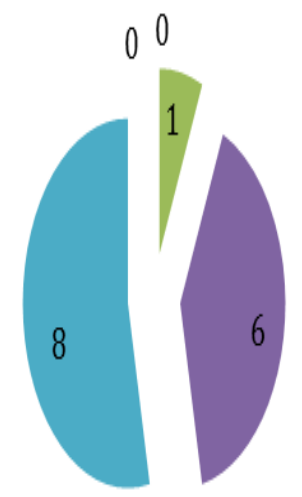

- Strongly disagree

- Disagree

Uncertain

Agree

- Strongly Agree

Fig. 8. Question 6

Figure 7 indicates that $9(93 \%)$ of the respondents believe that the application provides quick, positive feedback on the acceptance or rejection of data entry. Figure 8 shows that 14 (93\%) of respondents believe that they get the site information quickly.

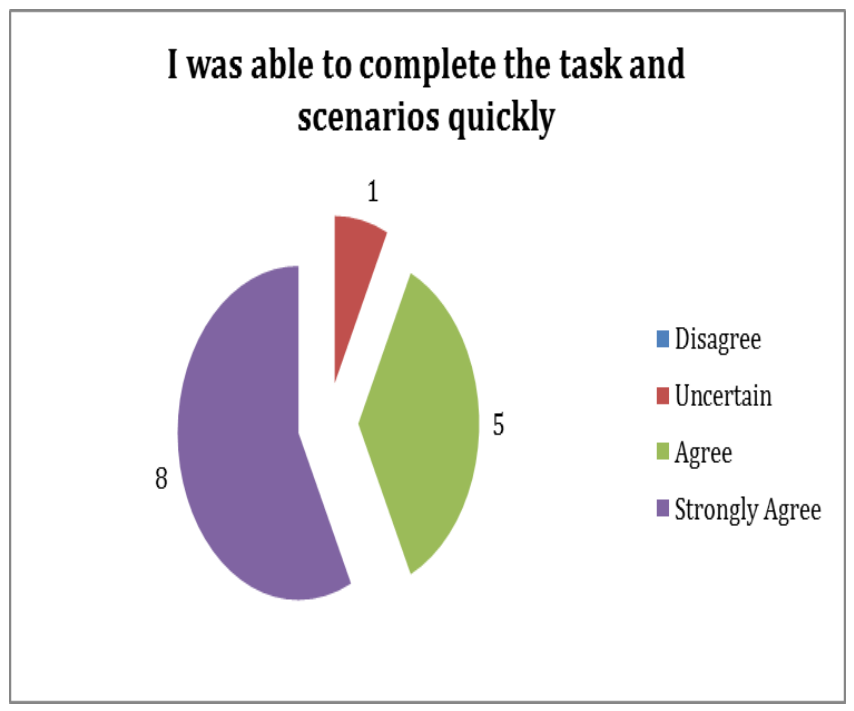

Fig. 9. Question 7 


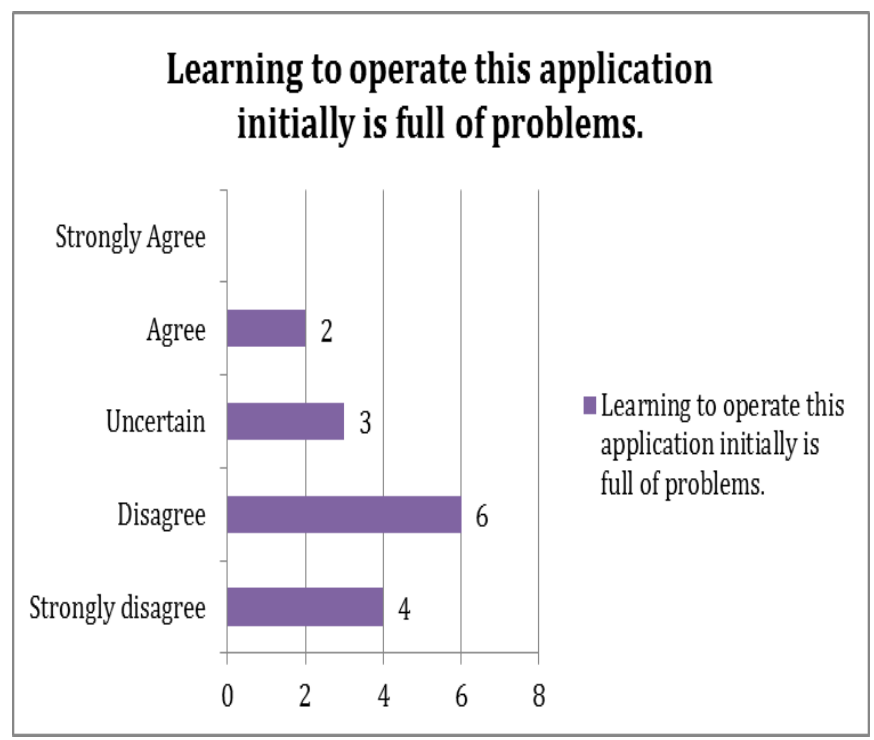

Fig. 10.Question 8

In addition, Figure 7 indicated that 13 respondents (87\%) perceived that they were able to complete their tasks and scenarios quickly.

\subsection{Learning}

Figure 10 indicates that $10(67 \%)$ respondents disagreed that learning to operate the application initially was full of problems.

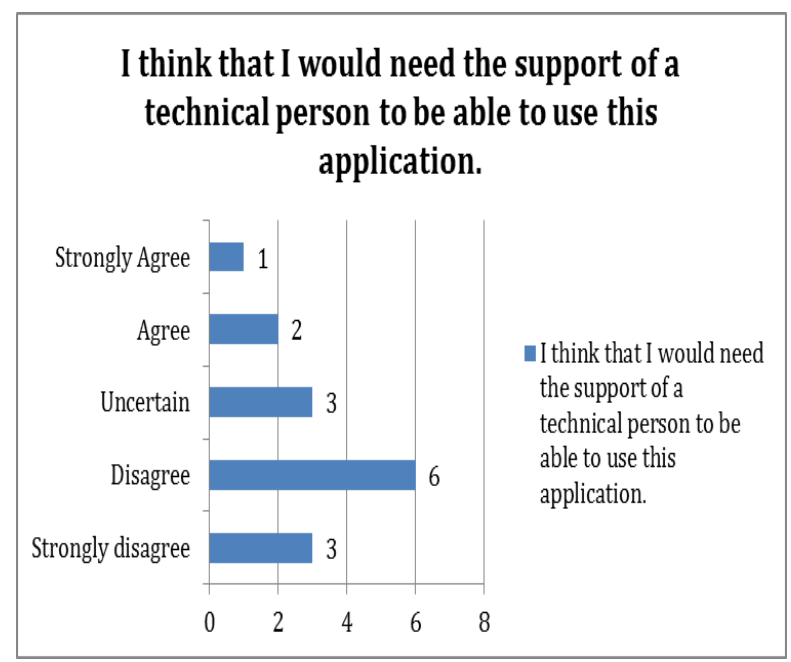

Fig. 11.Question 9 


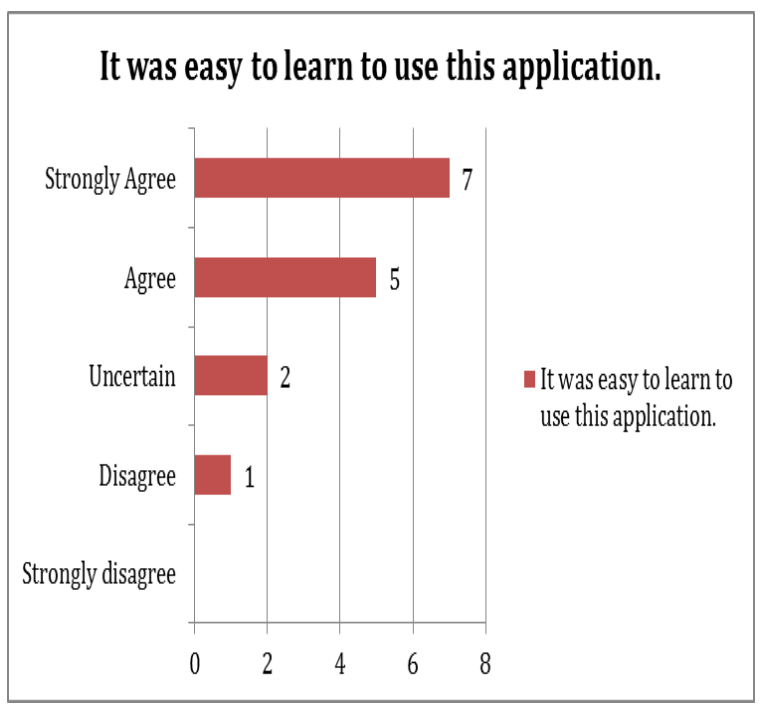

Fig. 12.Question 10

Figure 11 shows that $9(60 \%)$ of the respondents did not perceive that they would need the support of a technical person to be able to use the application. More so, 12 $(80 \%)$ of the study participants were of the opinion that it was easy to learn to use the application.

\subsection{Interface}

Figure 13 revealed that $12(80 \%)$ of the respondents believe that the interface of the application was pleasant. In Figure 14, 11 (73\%) participants felt that the application has a very attractive presentation.

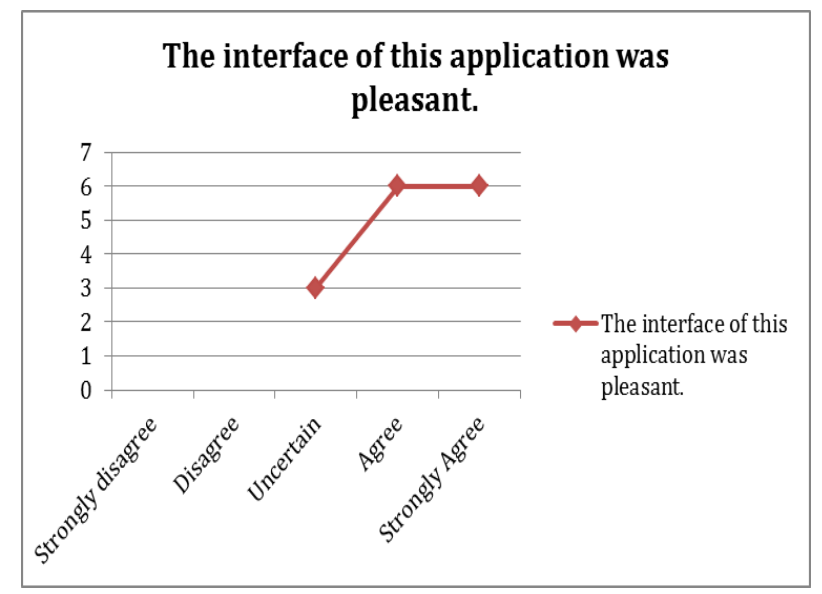

Fig. 13.Question 11 


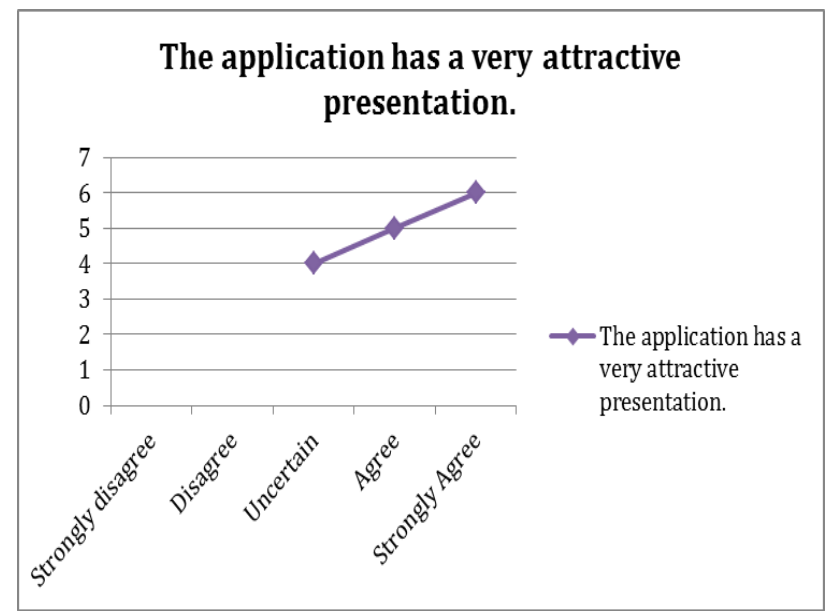

Fig. 14.Question 12

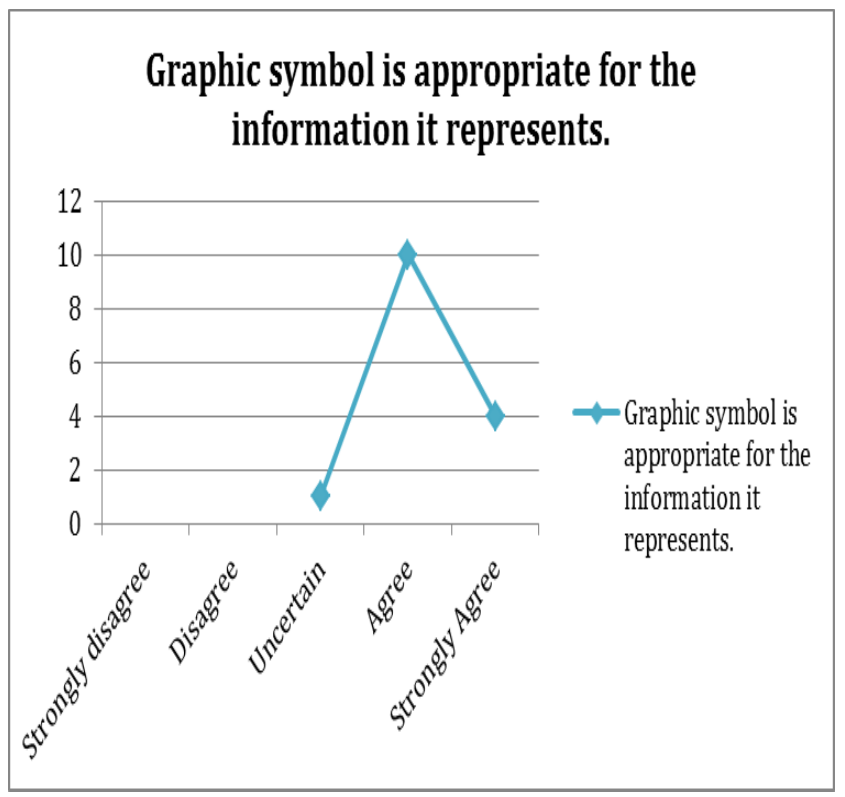

Fig. 15.Question 13 


\section{The application user friendly and easy to}

use.

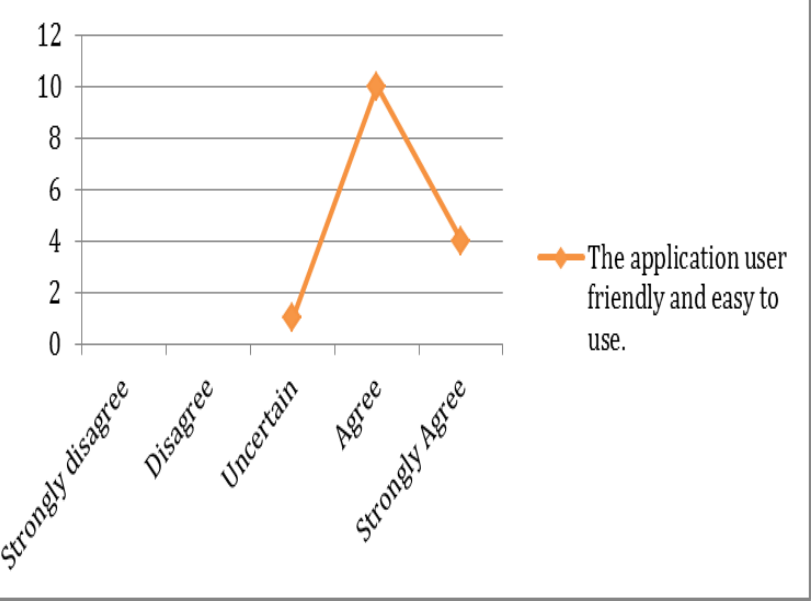

Fig. 16.Question 14

Figure 15 shows that 14 (93\%) of the respondents perceived that graphic symbols are appropriate for the information they represent. With regard to Figure 16, 14 (93\%) respondents believe that the application is user friendly and easy to use.

\subsection{End-User Satisfaction}

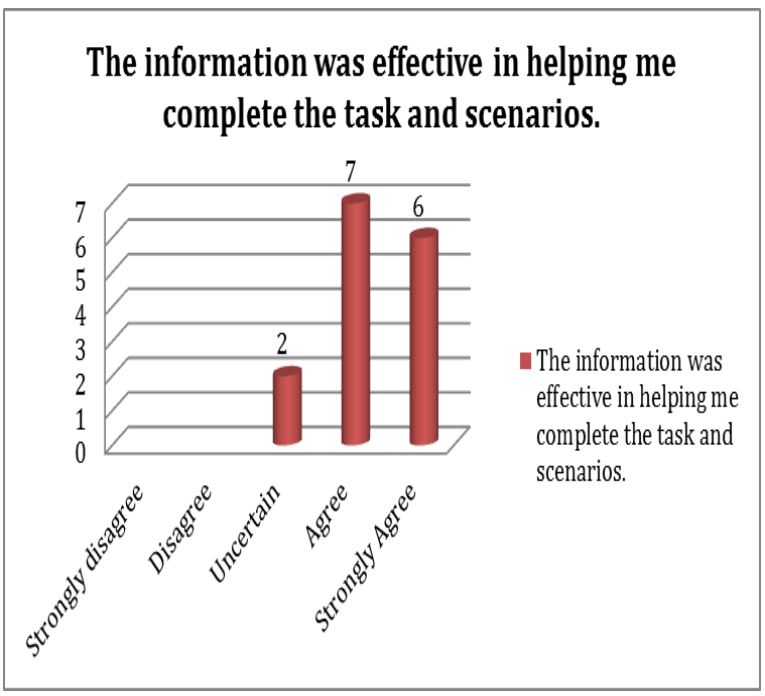

Fig. 17.Question 15 


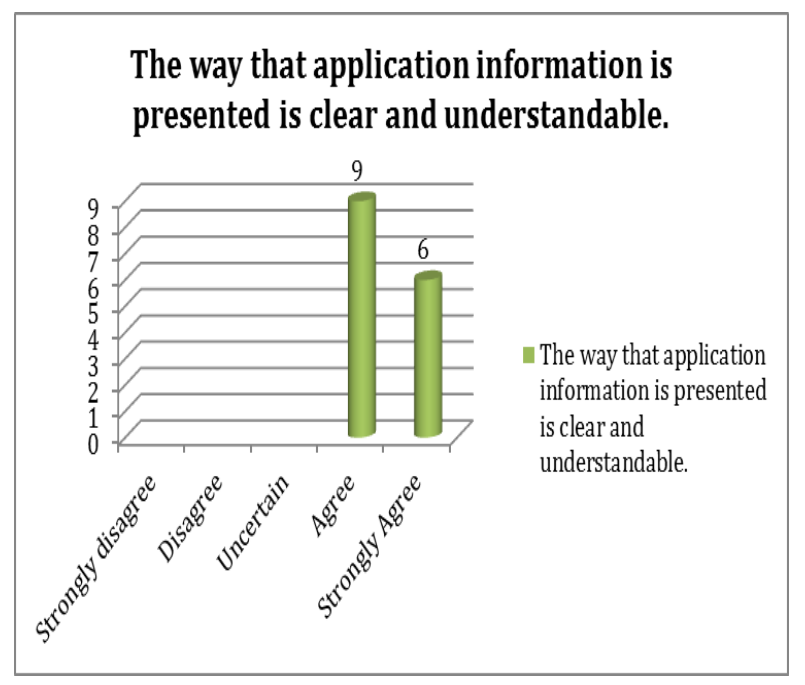

Fig. 18.Question 16

In Figure 17, 13 (87\%) of study participants believe that the information in the app was effective in helping them complete the tasks and scenarios. Figure 18 indicates that all respondents $(100 \%)$ believe that the application's information presented was clear and understandable. Figure 19 shows that $13(87 \%)$ of the respondents felt that tasks can be performed in a straightforward manner using the application. In Figure $20,14(93 \%)$ of the study participants perceived that overall, they were satisfied with how easy it is to use the application.

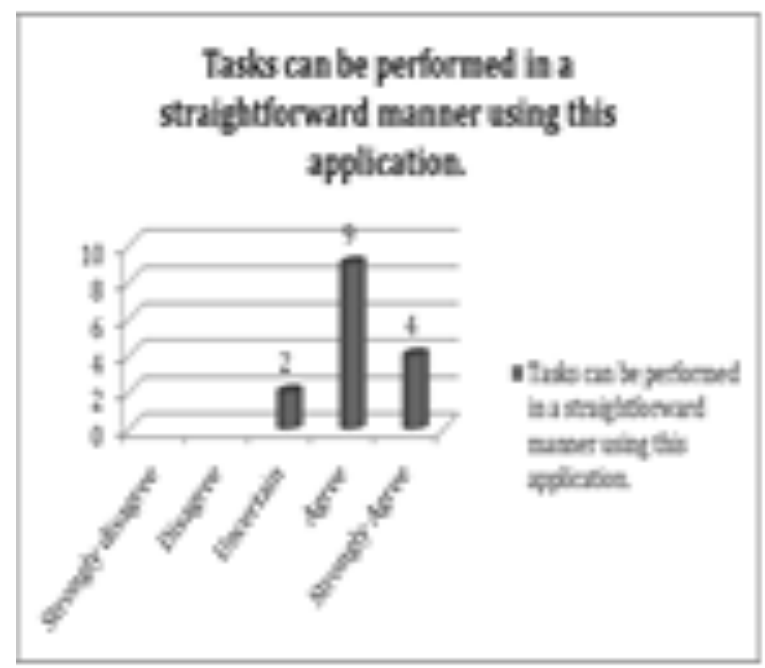

Fig. 19.Question 17 


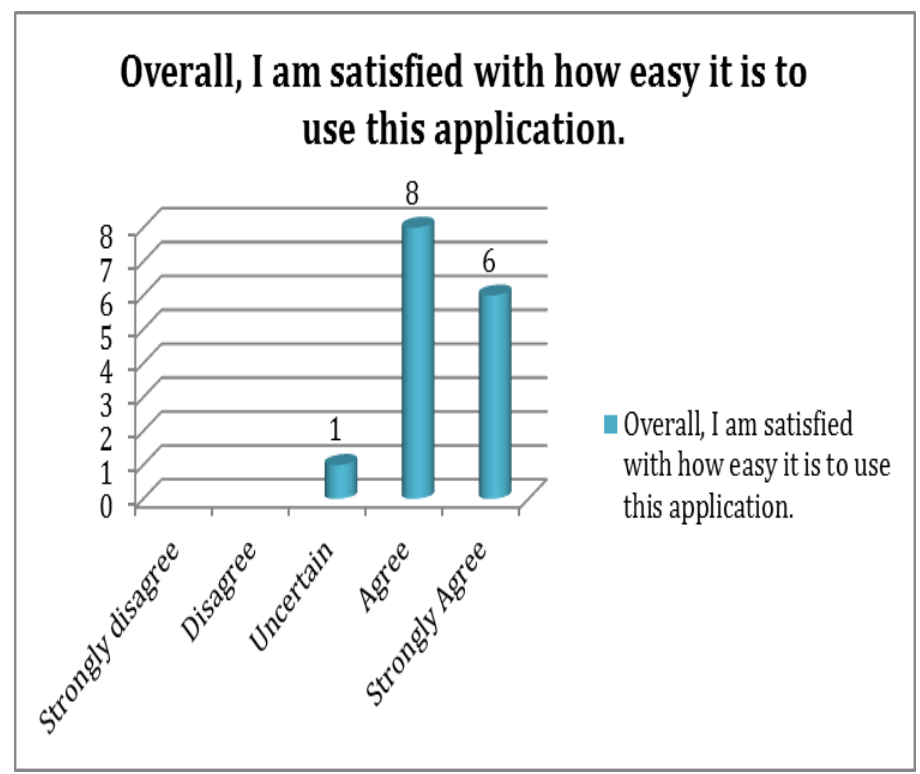

Fig. 20.Question 18

3.5 Loyalty

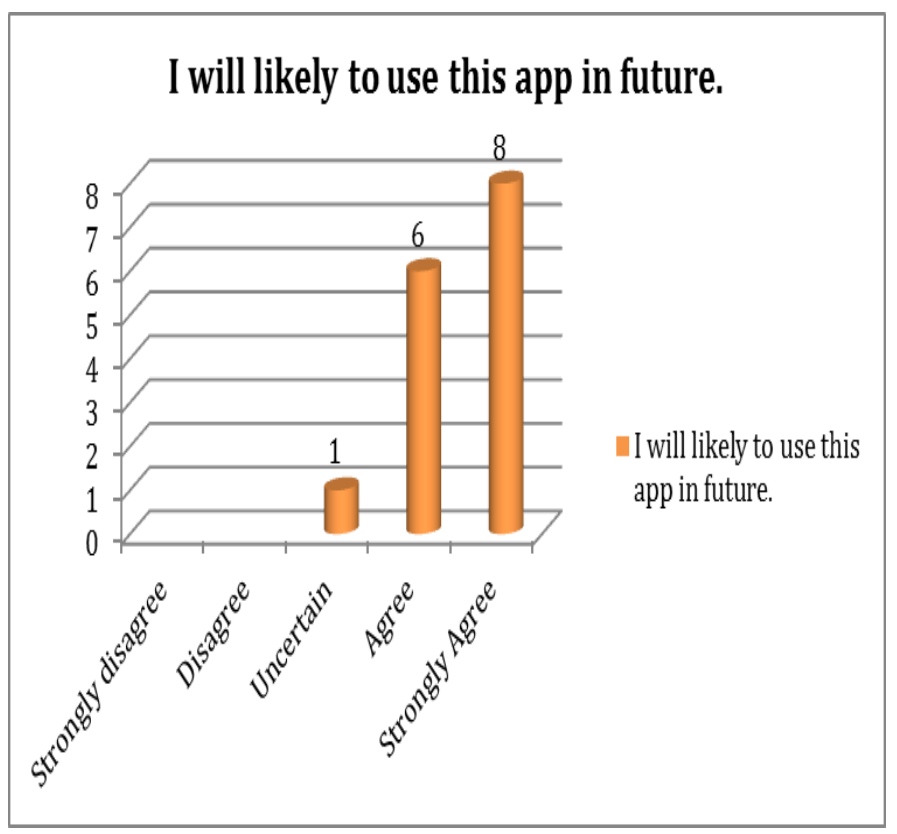

Fig. 21.Question 19 


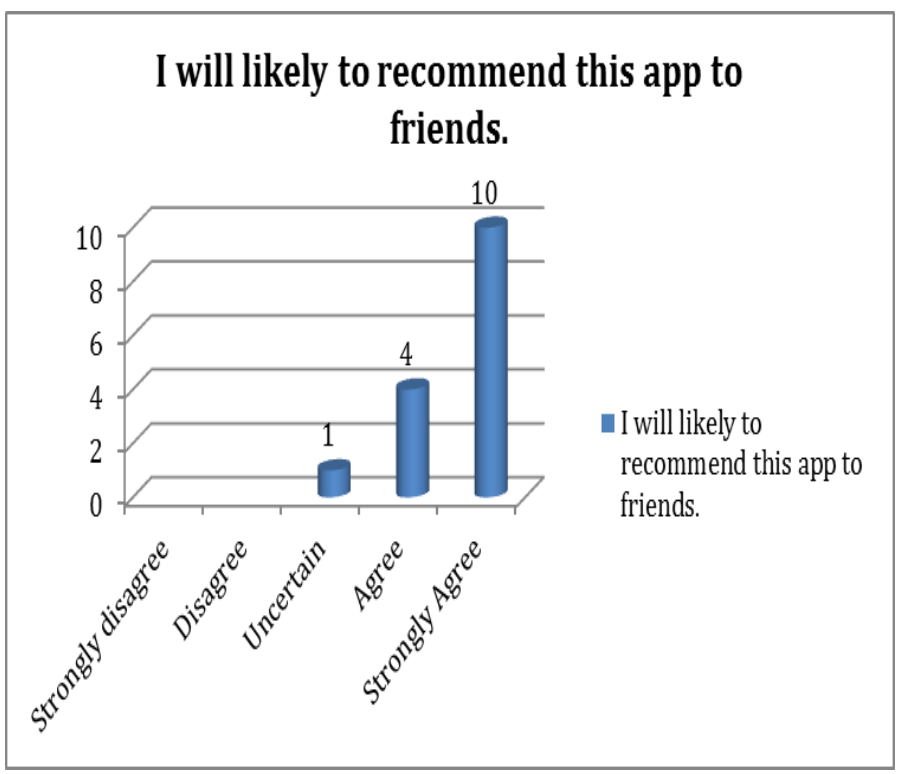

Fig. 22.Question 20

Figure 21 revealed that $14(93 \%)$ of the respondents indicated that they will likely to use the app in future. In Figure 22, 14 (93\%) of the respondents also indicated that they will likely recommend the app to friends.

\section{Conclusion}

A usability evaluation was conducted to assess the mobile expe-rience of the MyEG application. The think-aloud protocol was used. Also, the usability attributes of effectiveness, efficiency, and satis-faction with suitable metrics were used in assessing the app. The results showed that overall, the MyEG application promoted good and rich user experience. The study participants perceived that the app was usable and comfortable.

\section{$5 \quad$ References}

[1] Hussain, A, Mkpojiogu, EOC, Yahaya, NB \& Bakar, NZBA (2018), A mobile usability assessment of an m-shopping app. Journal of Advanced Research in Dynamical and Control Systems (JARDCS) 10 (SI), 1212-1217. https://doi.org/10.1063/1.5055455

[2] Gündüz, F \& Pathan, ASK (2013), On the key factors of usability in small-sized mobile touch-screen application. Int. J. Multimed. Ubiquitous Eng, 8(3), 115-138.

[3] Kaikkonen, A, Kekäläinen, A., Cankar, M, Kallio, T \& Kankainen, A (2005), Usability testing of mobile applications: A comparison between laboratory and field testing. Journal of Usability Studies, 1(1), 4-16. 
[4] Hussain, A, Mkpojiogu, EOC, Jamalsse, A \& Mohammed, RA (2018), Grab mobile app: a UX assessment on mobile devices. Journal of Advanced Research in Dynamical and Control Systems (JARDCS) 10 (SI), 1233-1238.

[5] Liu, F (2008), Usability Evaluations on Websites. School of Art \&Design, Wuhan University of Technology, Wuhan, Hubei Province, p: 141.

[6] Dumas, JS \& Redish, J (1999), A practical Guide to Usability Testing. Intellect Ltd, UK, US.

[7] Srivasta, J, Cooley, R, Deshpande, M \& Tan, PN (2000), Web Usage Mining: Discovery and Application of Web Usage Pattern from Web Data. Department of Computer Science and Engineering, University of Minnesota. https://doi.org/10.1145/846183.846188

[8] Mkpojiogu, EOC, Hussain, A \& Hassan, F (2018), A systematic review of usability quality attributes for the evaluation of mobile learning applications for children. ICAST 2018, AIP Conf. Proc. 2016, https://doi.org/10.1063/1.5055494

[9] Icela, L (2017), Usability evaluation focused on user experience of repositories related to energy sustainability : A Literature Mapping.

[10] Nayebi, F, Desharnais, JM \& Abran, A (2012), The state of the art of mobile application usability evaluation, 2012 25th IEEE Can. Conf. Electr. Comput. Eng., 1-4. https://doi.org/ $10.1109 /$ ccece.2012.6334930

[11] Paz, F \& Pow-Sang, JA (2014), Current Trends in Usability Evaluation Methods: A Systematic Review, 2014 7th Int. Conf. Adv. Softw. Eng. Its Appl., pp: 11-15. https://doi. org/10.1109/asea.2014.10

[12] Hussain, A, Mkpojiogu, EOC \& Suleiman, K (2018), A usability testing of a mobile print shop booking and design application. Journal of Advanced Research in Dynamical and Control Systems (JARDCS) 10 (SI), 1359-1365.

[13] Holzinger, A (2005), Usability engineering methods for software developers. Communications of the ACM, 48(1), 71-74. https://doi.org/10.1145/1039539.1039541

[14] Molich, R, \& Wilson, C (2008), Tips and tricks for avoiding common problems in usability test facilitation. CHI'08 extended abstracts on Human factors in computing systems. ACM, pp: 2379-2382. https://doi.org/10.1145/1358628.1358689

[15] Hussain, A, Mkpojiogu, EOC, Suleiman, K \& Alhussian, H (2018), A heuristic evaluation of a mobile print and design shopping application. Journal of Advanced Research in Dynamical and Control Systems (JARDCS) 10 (SI), 1457-1462. Buchanan, S, \& Salako, A (2009), Evaluating the usability and usefulness of a digital library. Library Review, 58(9), 638-651. https://doi.org/10.1108/00242530910997928

[16] Rubin, J \& Chisnell, D (2008), Handbook of Usability Testing: How to Plan, Design, and Conduct Effective Tests. Canada: John Wiley \& Sons, Inc.

[17] Hussain, A, Mkpojiogu, EOC, Abduljabbar, AM \& Almadhagi, AHG (2018). UUM mobile for students: a usability evaluation on two mobile OS platforms. Journal of Advanced Research in Dynamical and Control Systems (JARDCS) 10 (SI), 1514-1519. https://doi. org/10.1063/1.5055454

[18] Gündüz, F \& Pathan, ASK (2012), Usability improvements for touch-screen mobile flight booking application: A case study. 2012 International Conference on Advanced Computer Science Applications and Technologies (ACSAT), IEEE, pp: 49-54. https://oi.org/10.11 09/acsat.2012.9

[19] Dillon, A (2002), Beyond usability: process, outcome and affect in human-computer interactions. Canadian Journal of Library and Information Science.

[20] Mkpojiogu, EOC \& Hussain, A (2018), Assessing the influence of self-reported requirements importance on the perceived quality of proposed software products. ICAST 2018, AIP Conf. Proc. 2016, 020091, https://doi.org/10.1063/1.5055493 
[21] Ahmad, N, Boota, MW \& Masoom, AH (2014), Smart Phone Application Evaluation with Usability Testing Approach, J. Softw. Eng. Appl., 7(12), 1045. https://doi.org/10.4236/jsea. $\underline{2014.712092}$

[22] Brown, ME \& Hocutt, DL (2015), Learning to Use, Useful for Learning: A Usability Study of Google Apps for Education, J. Usability Stud., 10 (4), 160-181.

[23] Hussain, A, Mkpojiogu, EOC, Isse, AJ \& Mohammed, RA (2018), Grab mobile application: a usability evaluation. ICAST 2018, AIP Conf. Proc. 2016, 020054, https://doi. org/10.1063/1.5055456

[24] ISO 9241-11 (1998), Ergonomic requirements for office work with visual display terminals (vdts)-part 11: Guidance on usability. ISO Standard 9241-11: 1998. International Organization for Standardization. https://doi.org/10.3403/01822507u

[25] Hussain, A, Mkpojiogu, EOC, Yahaya, NB \& Bakar, NZBA (2018), A mobile usability assessment of carousell mobile app. ICAST 2018, AIP Conf. Proc. 2016. 020053, https://doi. org/10.1063/1.5055455

[26] Bartek, V \& Cheatha, MD (2003), Experience Remote Usability Testing, Part 2: Examine the Benefits and downside of Remote Usability Testing. http://www.mendeley.com/ research/experience-remote-usability-testing-part-2-examine-benefits-downside-remote-us ability-testing/ . https://doi.org/10.22215/etd/2003-05659

[27] Hussain, A, Mkpojiogu, EOC, Abduljabbar, AM \& Almadhagi, AHG (2018), A usability evaluation of UUM mobile for students app on IOS and android platforms. ICAST 2018, AIP Conf. Proc. 2016, 020052, https://doi.org/10.1063/1.5055454

[28] Chau, P. Cole, M, Massey, AP, Montoya-Weiss, M \& O'Keefe, RM (2002), Cultural differences in consumer's online behaviors. Commun. ACM, 45(10), 45-50. https://doi.org/10. $\underline{1145 / 570907.570911}$

[29] Hussain, A, Mkpojiogu, EOC \& Hassan, F (2018), Dimensions and sub-dimensions for the evaluation of m-learning apps for children: A review. International Journal of Engineering \& Technology (IJET) 7 (3.20), 291-295. https://doi.org/10.14419/ijet.v7i3.20.19168

[30] Forsell, C \& Johansson, J (2010), An heuristic set for evaluation in information visualization. Proceedings of the International Conference on Advanced Visual Interfaces, ACM, pp: 199-206. https://doi.org/10.1145/1842993.1843029

[31] Krippendorff, K (2004), Content Analysis: An introduction to its methodology, (Sage Publications Inc., United States, 2004).

[32] Gehrke, D \& Turban, E (1999), Determinants of successful website design: Relative importance and recommendations for effectiveness, Proc. 32nd Hawaii Int. Conf. System Sciences. https://doi.org/10.1109/hicss.1999.772943

[33] Harrison, R, Flood, D \& Duce, D (2013), Usability of mobile applications: Literature Review and Rationale for A New Usability Model, 1-16. https://doi.org/10.1186/2194$\underline{0827-1-1}$

[34] Hussain, A \& Mkpojiogu, EOC (2015), An application of the ISO/IEC 25010 standard in the quality-in-use assessment of an online health awareness system, J. Teknol., 77(5) 9-13. https://doi.org/10.11113/jt.v77.6107

[35] El-Gayar, O, Timsina, P, Nawar, N, \& Eid, W (2013), Mobile applications for diabetes self-management: Status and potential, J. Diabetes Sci. Technol., 7(1), 247-262. https://doi.org/10.1177/193229681300700130

[36] Naismith, L (2004), Literature review in mobile technologies and learning, NESTA Futur. Ser. ; Rep. 11, p: 44.

[37] Hussain, A, Abd Razak, MNF, Mkpojiogu, EOC \& Hamdi, MMF (2017), UX evaluation of a video streaming application with teenage users. Journal of Telecommunication, Electronic \& Computer Engineering (JTEC), 9 (2-11), 129-131. 
[38] Naslund, JA, Aschbrenner, KA, Marsch, LA \& Bartels, SJ (2016), The future of mental health care: Peer-To-peer support and social media, Epidemiol. Psychiatr. Sci., 25 (2), 113-122. https://doi.org/10.1017/s2045796015001067

[39] Hussain, A, Isam, M \& Mkpojiogu, EOC (2017), A UX assessment of a mobile recommender app for household electrical energy savings. Journal of Telecommunication, Electronic \& Computer Engineering (JTEC), 9 (2-11)

[40] Joo, S, Lin, S \& Lu, K (2011), A Usability Evaluation Model for Academic Library Websites: Efficiency, Effectiveness and Learnability, J. Libr. Inf. Stud., 9(2), 11-26.

[41] Toribio-Guzmán, JM, García-Holgado, A, Pérez, FS, García-Peñalvo, FJ \& Martín, MAF (2016), Study of the Usability of the Private Social Network SocialNet using Heuristic Evaluation, Proc. XVII Int. Conf. Hum. Comput. Interact. - Interacción '16, pp: 1-5. https://doi.org/10.1145/2998626.2998674

[42] Hussain, A, Mkpojiogu, EOC \& Jasin, NMD (2017), Usability metrics and methods for public transportation applications: a systematic review. Journal of Engineering Science and Technology (JESTEC), Special Issue on ISSC'16, 4, 98-105.

[43] Chiang, KP \& Dholakia, RR (2003), Factors Driving Consumer Intention to Shop Online: An Empirical Investigation, Journal of Consumer psychology, 13(1\&2), 177-183. https:// doi.org/10.1207/s15327663jcp13-1\&2_16

[44] Hussain, A, Isam, M \& Mkpojiogu, EOC (2017), A UX assessment of a mobile recommender app for household electrical energy savings. Journal of Telecommunication, Electronic \& Computer Engineering (JTEC), 9 (2-11)

[45] Bangor, A, Kortum, P \& Miller, J (2009), Determining what individual SUS scores mean: Adding an adjective rating scale. Journal of Usability Studies, 4(3), 114-123.

[46] Hussain, A, Mkpojiogu, EOC, Musa, J \& Mortada, S (2017), A user experience evaluation of amazon kindle mobile application. Proceedings of the $2^{\text {nd }}$ International Conference on Applied Science and Technology (ICAST'17), Kedah, Malaysia. AIP Conference Proceedings 1891 (1), 020060, https://doi.org/10.1063/1.5005393

[47] Nielsen, J (1993), Usability Engineering, Academic Press, United States.

[48] Hussain, A, Mkpojiogu, EOC, Fadzil, NM \& Hassan, NM (2017), The UX of amila pregnancy on mobile device. Proceedings of the $2^{\text {nd }}$ International Conference on Applied Science and Technology (ICAST'17), Kedah, Malaysia. IP Conference Proceedings 1891 (1), 020061, https://doi.org/10.1063/1.5005394

[49] Kiseol, Y \& Hye-Young, K (2012), Mobile shopping motivation: an application of multiple discriminant analysis, International Journal of Retail \& Distribution Management, 40(10), 778-789. https://doi.org/10.1108/09590551211263182

[50] Hussain, A, Mkpojiogu, EOC, Abubakar, H \& Hassan, HM (2017), The usability evaluation of mudah.my on mobile device. Proceedings of the $2^{\text {nd }}$ International Conference on Applied Science and Technology (ICAST'17), Kedah, Malaysia. AIP Conference Proceedings 1891 (1), 020058; https://doi.org/10.1063/1.5005391

[51] Ferré, X, Juristo, N, Windl, H \& Constantine, L, Usability engineering Usability Basics, IEEE Softw., 18. https://doi.org/10.1109/52.903160

[52] Hussain, A, Mkpojiogu, EOC, Jamaludin, NH \& Moh, STL (2017), A usability evaluation of Lazada mobile application. Proceedings of the $2^{\text {nd }}$ International Conference on Applied Science and Technology (ICAST'17), Kedah, Malaysia. AIP Conference Proceedings 1891 (1), 020059, https://doi.org/10.1063/1.5005392

[53] Limayem, M, Khalifa, M \& Frini, A (2000), What make consumer buy from internet? A Longitudinal study of online shopping. IEEE Transactions on Systems, Man, and Cybernetics - Part A: Systems and Humans, 30(4). https://doi.org/10.1109/3468.852436 


\section{Authors}

Azham Hussain is the Associate Professor of Software Engineering at School of Computing, Universiti Utara Malaysia, Kedah, Malaysia. He is the founder of Human-Centered Computing Research Group, which is affiliated with the Software Technology Research Platform Center at School of Computing, Universiti Utara Malaysia. Azham Hussain is a member of the US-based Institute of Electrical and Electronic Engineers (IEEE), and actively involved in both IEEE Communications and IEEE Computer societies.

Emmanuel O.C. Mkpojiogu is a Lecturer at Department of Computer and Information Technology, Veritas University, Abuja, Nigeria. Currently, he is a PhD student at School of Computing, Universiti Utara Malaysia. The research area is User Experience, Human Computer Interaction and Software Engineering. He has published many articles in reputable Scopus indexed journals. mkpojiogue@gmail.com

Norzila Ishak is a lecturer at Department of Information Technology and Communication, Politeknik Seberang Perai, PermatangPauh, Penang. Her research focus on Human Computer Interaction and User Experience.

Nurhidayah Mokhtar is a lecturer at Department of Information Technology and Communication, Politeknik Seberang Perai, PermatangPauh, Penang. She has completed her master's in information technology and looking forward to further to $\mathrm{PhD}$ in Human Computer Interaction or Software Requirement for mobile.

Article submitted 2019-07-16. Resubmitted 2019-09-03. Final acceptance 2019-09-10. Final version published as submitted by the authors. 